\title{
Dipsiz-Çine Çayı (Aydın)'nda Yaşayan Tatlısu Midyesi Unio crassus (Philipsson, 1788) Populasyonunun Morfometrik Özellikleri"
}

\author{
Özgen Yılmaz*, Murat Barlas
}

Muğla Sitkı Koçman Üniversitesi, Fen Fakültesi, Biyoloji Bölümü, 48000 Muğla, Türkiye

M A K A L E B İ L G İ S İ

${ }^{\#}$ Bu çalışma, yüksek lisans tezinden hazırlanmiştır.

Geliş 26 Mayıs 2016

Kabul 26 Ağustos 2016

Çevrimiçi bask1, ISSN: 2148-127X

Anahtar Kelimeler:

Morfometri

Dipsiz-Çine Çayı

Unio crassus

Tatlısu midyesi

Baraj

*Sorumlu Yazar:

E-mail: ozgenylmz@gmail.com

\section{Ö Z E T}

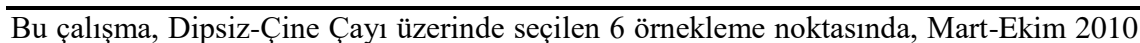
tarihleri arasında elde edilen 176 bireyin morfometrik özelliklerini belirlemek amaciyla yürütülmüştür. Dipsiz-Çine Çayı'nda dağılım gösteren Unio crassus (Philipsson, 1788)'un morfometrik özellikleri ve bulunan birey sayılarının aylara ve örnekleme istasyonlarına göre dağılımları incelenmiştir. Arazide elle toplanan, kumpas ve hassas terazi kullanılarak ölçümleri kaydedilen toplam 176 bireye ait ağırlık $(\mathrm{g})$, genişlik $(\mathrm{mm})$, uzunluk $(\mathrm{mm})$ ve yükseklik $(\mathrm{mm})$ verileri aylara ve örnekleme istasyonlarına göre kıyaslanmış ve dağılımın aylık görüntüsü ortaya çıkarılmıştır. Çalışma sonunda tatlısu midyelerinin en fazla birey sayıs1, IV. örnekleme istasyonundan 115 birey olarak belirlenmiştir. En düşük birey sayısı ise II. örnekleme noktasında 1 birey olarak belirlenmiştir. Çine Adnan Menderes Barajı'nın kurulmasından önce elde edilen verilere dayanan bu çalışma ile Unio crassus'a ait veri havuzuna katkı sağlanması hedeflenmiştir.

Turkish Journal Of Agriculture - Food Science And Technology, 4(10): 877-881, 2016

Morphometric Features of Freshwater Mussel Unio crassus (Philipsson, 1788) Population Inhabiting Dipsiz-Çine Stream (Aydin)

\section{A R T I C L E I N F O}

\section{Article history:}

Received 26 May 20016

Accepted 26 August 2016

Available online, ISSN: 2148-127X

Keywords:

Morphometry

Dipsiz-Çine Stream

Unio crassus

Freshwater mussel

Dam

*Corresponding Author:

E-mail: ozgenylmz@gmail.com

\section{A B S T R A C T}

Recent study was carried out on 6 sampling stations chosen from Dipsiz-Çine Stream between March-October 2010 to determine the morphometric features of 176 specimens collected. In the extent of current study, data related with weight, width, length and height, and distribution of individual numbers of Unio crassus, which is inhabiting Dipsiz-Çine Stream, according to months and sampling stations were presented. 176 individuals of Unio crassus were caught by hand and measured by use of caliper and precision scale, and weight, width, length, height parameters were compared according to months and sampling points, and a monthly image of this distribution was presented. Maximum number of mussel individuals determined as 115 from IV. sampling point. Lowest numbers of individuals were found from II. sampling point as 1 . It is aimed to contribute to data pool of Unio crassus by this study which includes data concerning the time before the construction of Çine Adnan Menderes Dam.

\section{Giriş}

Başta nehirler olmak üzere tatlısu ortamları, dünyanın en çok tehditle karşı karşıya olan ekosistemleridir. Genel olarak uygun koruma önlemlerinin alınması için akarsuların kalitesinin, fiziksel, kimyasal ve biyolojik parametreler 1şı̆̆ında değerlendirilmesi gerekmektedir (Yorulmaz ve ark., 2015). Biyolojik parametrelerin değerlendirilmesinde tatlısu midyelerine ilişkin değerler dikkate değer ölçüde bilgiler sunmaktadır.
Tatlısu midyeleri üç alt sınıf içindeki 19 familyaya ait türleri kapsar ve Unioniformes takımı altında 6 familya, 180 cins ve 800 türü barındırır (Bogan, 2008). Bu türlerden biri olan Unio crassus, pek çok alttürü ve 353 sinonimi (Mussel, 2016) olan yaygın çeşitliliğe sahip bir tür olarak değerlendirilmektedir. Bu türün Atlantik'ten Ural Dağları'na, tüm Avrupa boyunca, Frrat-Dicle bölgesi ve Amur Havzası'na kadar yayılış sergilediği rapor 
edilmiştir. Türün yayılış özellikleri önceleri devamlıyken, günümüzde yayılış alanı boyunca aşırı derecede parçalıdır (Lopes-Lima ve ark., 2014).

Pek çok tatlı su midyesi için geçerli olduğu gibi Unio crassus da tabanı yumuşak kumlu veya kum ve taş karışımı olan, akıntının çok şiddetli olmadığı, sudaki çözünmüş oksijen miktarının yüksek ve besin stoğunun zengin olduğu ve uygun konak balıkların bulunduğu akarsularda veya akarsu kesimlerinde yaşar (Watters, 1992). Uygun konak balıkların (Chondrostoma nasus, Cottus gobio, Leuciscus idus, Phoxinus phoxinus, Squalius cephalus, Scardinius erythrophthalmus ve Gasterosteus aculeatus'un 3 farklı suşu) (Taeubert ve ark., 2012) varlığı, yeterli genişlikteki akarsu havzalarının bulunmasına bağlıdır. Çünkü daha geniş akarsu havzası daha fazla su içerir ve bu durum, balıklar için daha geniş habitat anlamına gelir. Balık populasyonlarının genişlemesi ve balık çeşitliliğinin artması, midye populasyonlarının genişlemesini ve midye çeşitliliğinin artmasını teşvik eder (Arey, 1921). Balık konakların önemi midyelerin hayat döngülerindeki rollerinden ileri gelir. Tatlı su midyeleri üremelerinin ardından oluşan larvalarının (glochidium) mutlaka bir balık konağa tutunmasını sağlamalıdır. Aksi takdirde larvalar kısa sürede ölürler. $\mathrm{Bu}$ tutunmayı sağlamak adına tatlı su midyeleri, yemler ve larva paketleri (konglutinat) adı verilen yöntemler geliştirmiştir (Chamberlain, 1934).

Unio crassus balık şeklindeki manto uzantılarına sahip olmadığından yemleme yöntemini değil, larval paket salınımını kullanır (Meglitsch ve Schram, 1991). Bu paketlere yaklaşan balıkların atakları paketleri patlatır ve larvalar balığa tutunur ve balık dokuları ile beslenir. Erişkin tatlı su midyeleri oksijen ve besin ihtiyaçlarını akarsu ortamındaki suyu süzerek giderirler. Besinlerini alg/alüvyon karışımı oluşturur. Tatlı su midyeleri iyi biyoindikatörlerdir. Tatlı su ortamında ortaya çıkan kirlilik, şayet tatlı su midyelerinin populasyon büyüklüğüne, üremelerine, dağılımlarına olumsuz yönde etki ediyorsa ortamda yaşayan diğer canlıların ve su kalitesinin tehdit altında olduğu anlaşılabilir (Nichols ve Newton, 2008; Oehlmann ve Oehlmann, 2003).

Habitatlarda insan müdahalesi ile yapılan değişiklikler, besin zincirinin ve ekolojik ağın her noktasını etkilemektedir. Doğal ortamda bu şekilde değişen organik ve inorganik madde içeriği, tür kompozisyonunun ve mevcut türlerin özelliklerinin bilimsel yollarla izlenmesini gerektiren şartları zorunlu kılmaktadır. Bu noktada, (dünyadaki pek çok örnekte de

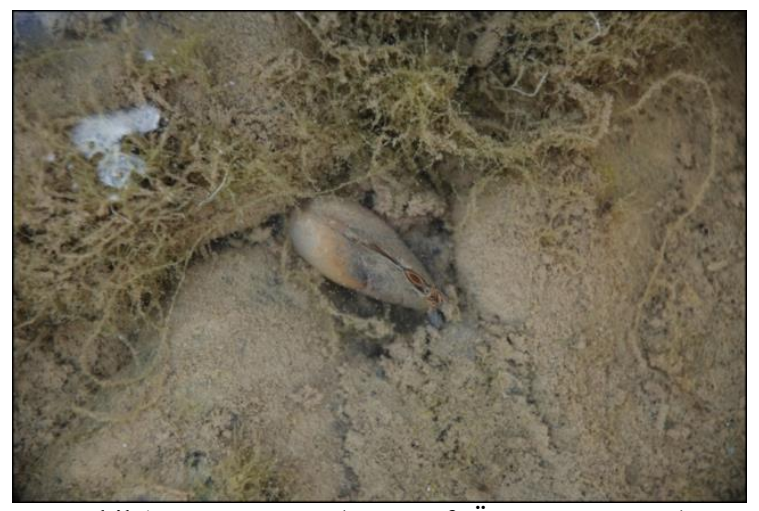

Şekil 1 Unio crassus (Fotoğraf: Özgen YILMAZ) olduğu gibi) karşılaştırmalı çalışmaların varlığının, habitatları tüm bileşenleri ile tanımlamada önemli bir yer tuttuğu görülmektedir. Çoğu kez, hakkında geçmişe ilişkin verilerin bulunmadığı biyolojik varlıkların gelecekteki durumlarını öngörmek ve gerekli önlemleri almak olanaksızlaşmaktadır. Bu çalışma ile Dipsiz-Çine Çayı'nda yaşayan tatlısu midyesi (Unio crassus) populasyona ilişkin morfometrik verilerin daha iyi tanınması ve gelecekte alınabilecek önlem basamaklarının oluşturulması amaçlanmaktadır. Belirtilen amaç doğrultusunda mevcut çalışma, Dipsiz-Çine Çayı'nın unionid midyelerine ilişkin bilgileri sunan ilk çalışma olma niteliğindedir.

\section{Materyal ve Yöntem}

Dipsiz-Çine Çayı'nda bulunan Unio crassus (Şekil 1) örnekleri, Mart-Ekim 2010 tarihleri arasında seçilen altı örnekleme noktasının beşinden toplanmıştır (Şekil 2). Örnekleme noktalarında midyeler, littoral bölgeden ve suyun en fazla $50 \mathrm{~cm}$ derininden, elle ve göz açıklığı 5 $\mathrm{mm}$ olan kepçe ile toplanmıştır (WFD, Directive 2000/60/EC (I), 2000). Toplanan bireyler laboratuar ortamına, 25 L'lik plastik kaplara konulan $5 \mathrm{~cm}$ yüksekliğindeki örnekleme noktası sedimenti ve $15 \mathrm{~cm}$ yüksekliğindeki örnekleme noktası suyu ile taşınmıştır. 25 L'lik kaplardaki midye sayısının 15'i geçmemesine dikkat edilmiştir. Bunun haricinde ek kap ve şişelerde örnekleme noktalarından sediment ve sular getirilmiştir. Araziden getirilen midyeler, asetat kalemiyle numaralandırılarak bulundukları örnekleme noktalarına göre ayrı ayrı kaplarda korunmuştur. Midyelerin, milimetre cinsinden vücut ölçüleri (uzunluk, genişlik, yükseklik) ve gram cinsinden ağırlıkları ölçülmüştür. Vücut ölçüleri alınırken 0,02 mm duyarlilıkta olan Max Extra marka kumpas kullanılmıştır (Nagel ve ark., 2015). Uzunluk, midyenin anterior ve posterior uçları arasındaki en uzun mesafe, yükseklik midyenin dorso-ventral hattı boyunca bulunan en uzun mesafe ve genişlik midyenin sağ ve sol kapağı boyunca uzanan en uzun mesafe dikkate alınarak ölçülmüştür. Ölçümü alınan midye örnekleri daha sonra yaşam alanlarına, onlara zarar verilmeden bırakılmıştır. Boy-ağırlık ilişkilerinin hesaplanmasında $\mathrm{W}=\mathrm{a}^{*} \mathrm{~L}^{\mathrm{b}}$ formülü ve bu formülün logaritmik dönüşümü yapılmış hali $(\log (\mathrm{W})=\mathrm{a}+\mathrm{b} * \log (\mathrm{L}))$ kullanılmıştır (Zar, 1999; Ogle, 2013). Verilerin istatistiki olarak, tanımlayıcı tablo ve regresyon analizi kullanılarak, işlenmesinde Excel ${ }^{\circledR}$, 2007 ve MedCalc v.14 kullanılmıştır.

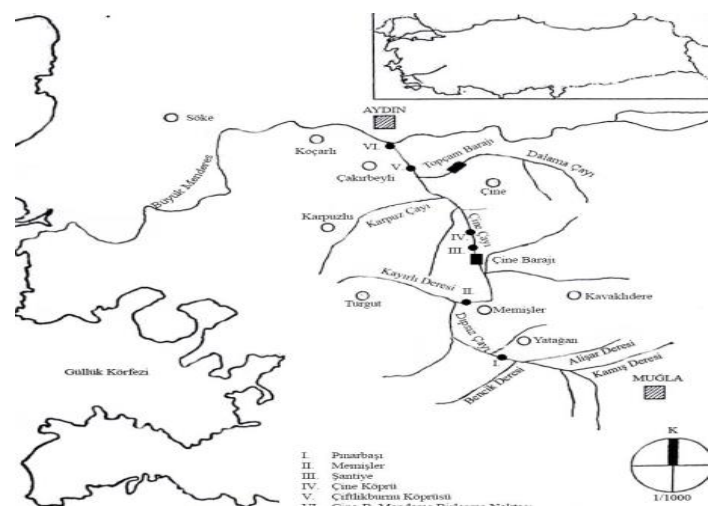

Şekil 2 Dipsiz-Çine Çayı üzerinde seçilen çalışma istasyonları 


\section{Bulgular}

Dipsiz-Çine Çayı'ndan örneklenen Unio crassus bireylerinin ağırlık, uzunluk, genişlik ve yükseklik parametrelerine ilişkin en düşük değerler sırasıyla 0,915 $\mathrm{g}, 12,56 \mathrm{~mm}, 9,32 \mathrm{~mm}$ ve $8,44 \mathrm{~mm}$ 'yken en yüksek değerler sirasıyla $55,887 \mathrm{~g}, 77,18 \mathrm{~mm}, 26,52 \mathrm{~mm}$ ve 40,6 mm'dir. Toplam verilere ilişkin özet Tablo 1'de verilmiştir. Örnekleme istasyonlarında bireyin bulunurluğu açısından, 2. örnekleme istasyonunun en fakir $(\mathrm{N}=1), 4$.'nün ise en zengin $(\mathrm{N}=115)$ olduğu tespit edilmiştir. 1. örnekleme noktasından ise arazi çalışmaları boyunca örnek toplanamamıştır. Bu durumun sebebi ise ilk örnekleme noktasının akarsuyun kaynağı olması ve taban yapısının midye bulunurluğu için elverişli olmamasidır.

Çalışma süresince, 2010 yılının Mart ve Nisan aylarında hiçbir örnekleme noktasında midye bireyine rastlanmamıştır. $\mathrm{Bu}$ durum, habitat koşullarının midye bulunurluğunu teşvik etmediği kış ve bahar ayları için olağan bir sonuçtur. Bu aylardan sonra midyeler en az 2 örnekleme noktasında (Temmuz ve Ekim aylarında) bulunmuştur. Örnekleme ilişkin istasyon zenginliğine Eylül ayında rastlanmıştır $(2,3,4,5$ ve 6 . örnekleme noktalar1). Ağustos ayında en fazla birey (78 birey) tespit edilmiştir. Fakat Ağustos ayında bu sayıya sadece bir istasyonda ulaşılmıştır (Şekil 3). Yaz aylarında özellikle sıcaklıkların artışı midyelerin akarsudaki bulunurluğunu olumsuz etkilemektedir.

Örneklerin genişlik ve uzunluk ilişkisinin sunulduğu Şekil 4'e göre bu veriler arasında doğrusal bir ilişki $(\mathrm{G}=0,3738 \mathrm{U}-0,4175)$ vardır $\left(\mathrm{R}^{2}=0,8101\right)$. Uzunluk verilerinin birlikte artışına işaret eden bu durum, canlının kabuk gelişiminde etkili olan çevresel şartlarda (sudaki $\mathrm{CaCO}_{3}$ miktarı, sicaklık gibi) meydana gelecek bir bozulmanın kabuk oluşumuna tüm yönleriyle etki edeceğini göstermektedir.

Şekil 5, Unio crassus'a ait ağırlık-uzunluk ilişkilerini ve veriler arasındaki regresyon analizine göre belirgin bir üstel ilişkiyi $\left(\mathrm{A}=0,0002 \mathrm{U}^{2.8197}\right)$ göstermektedir $\left(\mathrm{R}^{2}=0,9772\right)$. Bireylerin uzunluk artışı ağırlıkla birlikte azalırken, ağırlık artışı devam etmektedir. Bu durum, veriler arasındaki negatif allometrik bir ilişkiye de işaret etmektedir.

Mevcut allometrik ilişkinin daha belirgin olarak gösterilebilmesi için elde edilen denklem, logaritmik olarak dönüştürülmüştür $(\log (\mathrm{A})=-3,6192+2,8197$ $\log (\mathrm{U}))$. Bu doğrusal dönüşümüne ilişkin sonuçlar Tablo 2'de sunulmuştur. Tablo 2'deki analiz sonuçlarına göre allometrinin gösterilmesi için kullanılan uzunluk ve ağırlık verileri arasında istatistiki açıdan anlamlı bir ilişki mevcuttur $(\mathrm{P}<0,05)$.

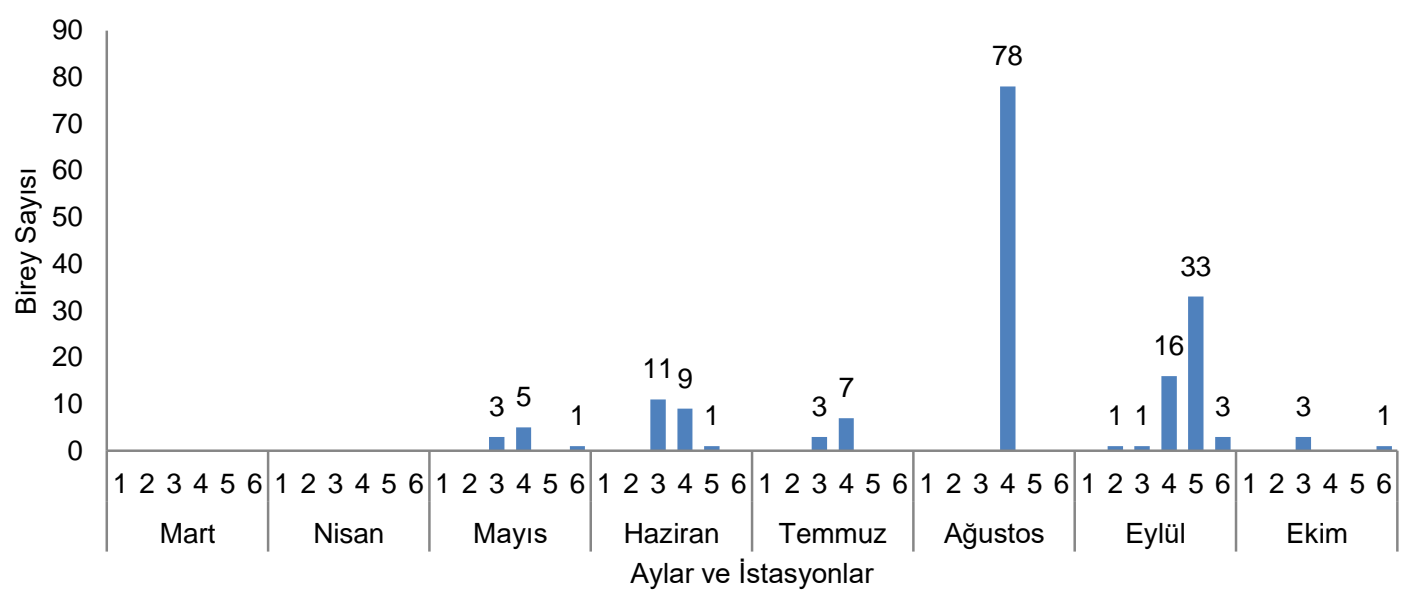

Şekil 3 İstasyonlar ve aylara göre birey sayısının dağılımı

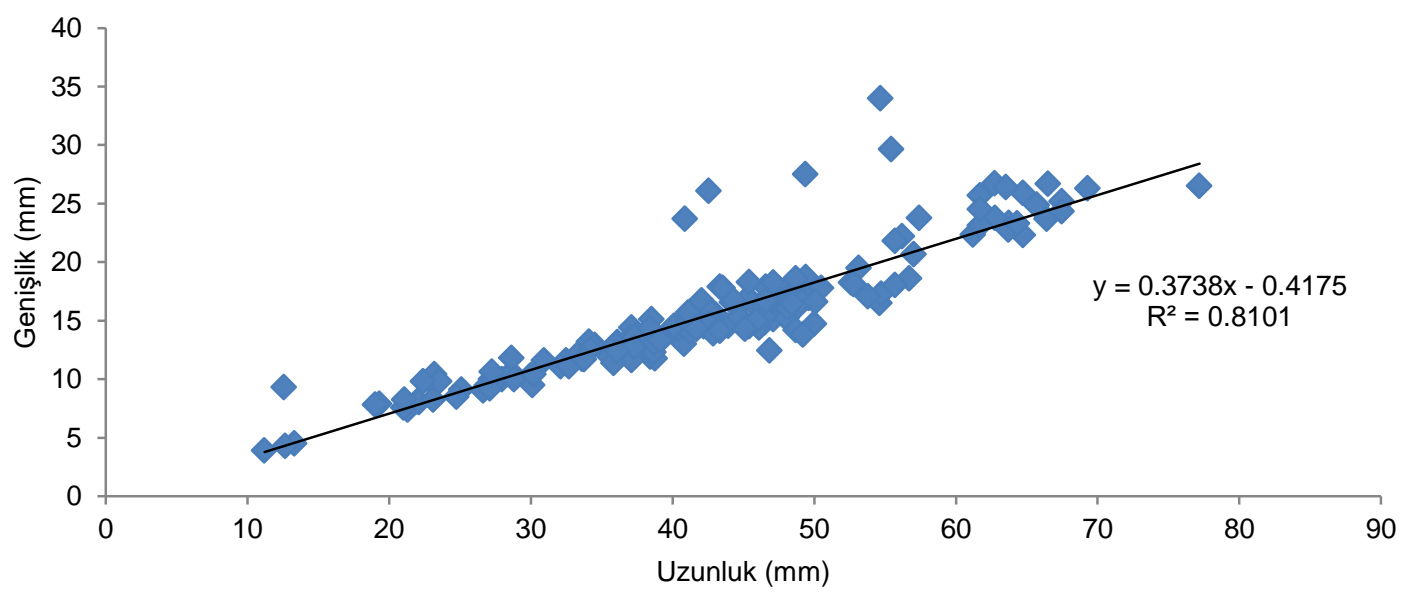

Şekil 4176 Unio crassus bireyinin genişlik-uzunluk ilişkisi 


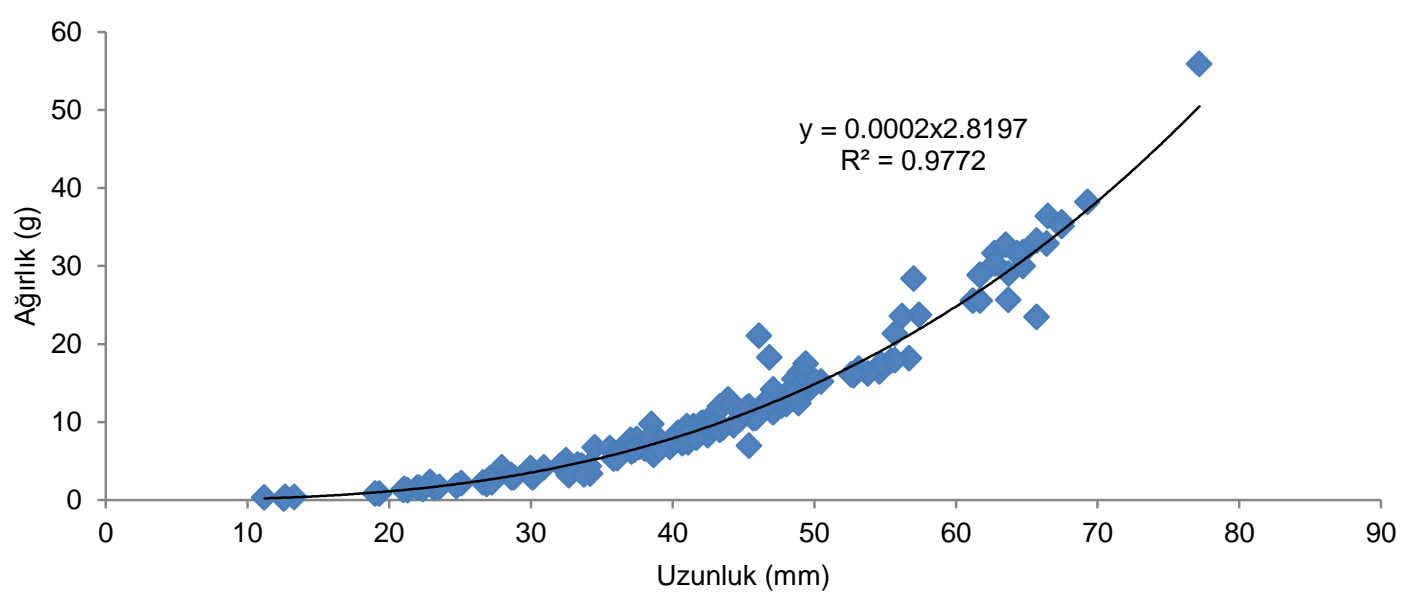

Şekil 5176 Unio crassus bireyinin ağırlık-uzunluk ilişkisi

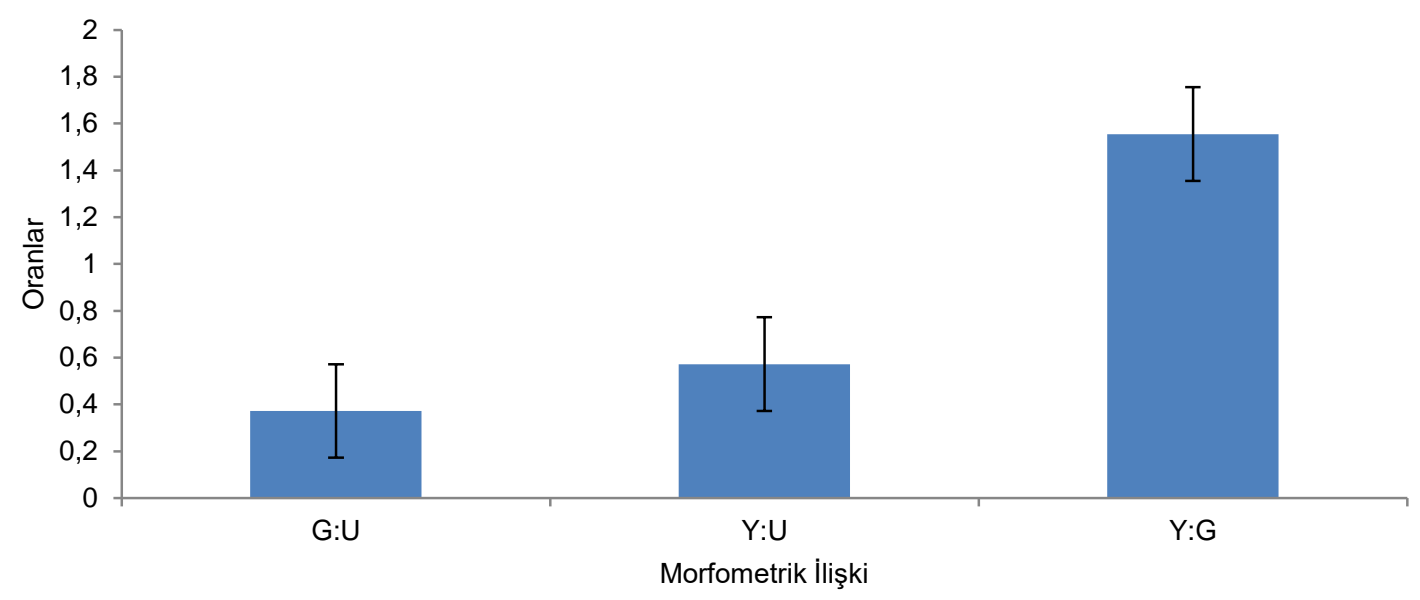

Şekil 6 Unio crassus'ta morfometrik ilişkiler (G: genişlik, U: uzunluk, Y: yükseklik) (Standart Hata: 0,2)

\section{Tartışma ve Sonuç}

Elde edilen sonuçlara göre, en fazla birey IV. istasyondan (115 birey) toplanmış ve Ağustos'ta en yüksek birey sayısının (78 birey) bulunduğu belirlenmiş̧tir. IV. istasyon, akarsu genişliği ve su bulunurluğu açısından midyeler için sağlıklı bir habitat ödevi gördüğü için buradaki midye sayıları yüksek olarak tespit edilmiştir. Bireylerin dağılımı istasyonlar ve aylar bazında incelendiğinde, 4 . istasyonun 8 ayın 5 'inde birey barındırdığı gözlenmiştir. Dipsiz Çine Çayı'ndan toplanan $U$. crassus'a ait örneklerin ağırlı değerleri $0,195 \mathrm{~g}$ ile $55,887 \mathrm{~g}$, uzunluk değerleri $12,56 \mathrm{~mm}$ ile $77,18 \mathrm{~mm}$, genişlik değerleri $9,32 \mathrm{~mm}$ ile $26,52 \mathrm{~mm}$ ve yükseklik değerleri $8,44 \mathrm{~mm}$ ile 40,6 $\mathrm{mm}$ arasında ölçülmüștür. Unio crassus'ta genişlik-uzunluk ilişkisi $\mathrm{G}=0,4186 \mathrm{U}^{0.9604}$ $\left(\mathrm{R}^{2}=0,8673\right) \quad$ ve ağılık-uzunluk ilişkisi ise $\mathrm{A}=0,0002 \mathrm{U}^{2.8197} \quad\left(\mathrm{R}^{2}=0,9772\right)$ olarak bulunmuştur. $\mathrm{Bu}$ sonuçlara göre uzunluk ve ağırlık arasında negatif allometrik bir ilişkinin olduğu tespit edilmiştir. Unio crassus'ta genişlik ve uzunluk verileri ise doğrusal ilişkiye sahiptir.

Kara (2004)'nın Unio pictorum'da tespit ettiği ağırlıkuzunluk ilişkileri $\left(\mathrm{W}=0,0022 \mathrm{~L}^{2.1045}\right)$ ile mevcut çalışmanın sonuçlarının benzerlik gösterdiği tespit edilmiştir. Ayrıca, Ercan ve ark. (2013), çalışmalarında regresyon katsayısı (b) değerini Unio crassus için 2.47 olarak tespit etmiştir.
Reategui-Zirena ve ark. (2013)'nin Pleurobema strodeanum'a ilişkin morfometrik sonuçlarına göre genişlik:uzunluk oranları yaşla artmakta fakat yükseklik:uzunluk oranları sabit kalmaktadır. Unio crassus'a ait genişlik:uzunluk, yükseklik:uzunluk ve yükseklik:genişlik oranları Şekil 6'da verilmiştir.

Mevcut çalı̧̧mada sunulmuş olan Unio crassus'a ait morfometrik özellikler, 2010 yılında Dipsiz-Çine Çayı üzerinde bulunan Çine Adnan Menderes Baraj1 kurulmadan önceki duruma işaret ettiğinden gelecekte aynı habitatta yapılacak çalışmalar için kıyaslamalı veriler sunacaktır. Mevcut tür IUCN Kırmızı Listesi'nde "tehdit altında" sınıfina dahil edilmiştir (Lopes-Lima ve ark., 2014). Pekçok insan kaynaklı faaliyet sonucu yapısında değişiklik yapılan Dipsiz-Çine Çayı'daki Unio crassus populasyonunun anlaşılmasına ve tanınmasına yönelik yapılan çalışmanın bilimsel açıdan katkı sağlaması hedeflenmektedir. Temel populasyon çalışmalarından, disiplinler arası koruma çalışmalarının tesis edilmesine kadar geniş bir yelpazeyi içine alan biyolojik araştırmalarda elde edilmiş tüm veriler, kayıtlar ve raporlar önem taşır. $\mathrm{Bu}$ çalışmanın da geçmiş dönemlere ilişkili kayıtları barındırması açısından önem taşıdığı düşünülmektedir. 
Tablo 1176 Unio crassus bireyine ilişkin uzunluk, genişlik, yükseklik ve ağırlık değerleri ( \pm Standart sapma)

\begin{tabular}{l|c}
\hline \multicolumn{1}{c|}{$\mathrm{N}$} & 176 \\
\hline Uzunluk (mm) & $42,60( \pm 12,56)$ \\
Genişlik (mm) & $15,50( \pm 5,21)$ \\
Yükseklik (mm) & $23,77( \pm 6,54)$ \\
Ağırlık (g) & $11,68( \pm 9,24)$ \\
\hline
\end{tabular}

Tablo 2 Uzunluk-ağırlık ilişkilerine ait regresyon analizi sonuçları (U: uzunluk, A: ağırlık, b: eğim, SH: standart hata, GA: güven aralığ $1, \mathrm{~N}=176)$.

\begin{tabular}{l|c}
\hline \multicolumn{1}{c|}{ Veriler } & $\mathrm{U}-\mathrm{A}$ \\
\hline $\mathrm{b}$ & 2,8197 \\
SH (b) & 0,03263 \\
$95 \%$ GA (b) & $2,7553-2,8841$ \\
$\mathrm{R}^{2}$ & 0,9772 \\
$\mathrm{t}$ & 86,4064 \\
F-oranı & 7466,069 \\
P & $<0,0001$ \\
\hline
\end{tabular}

\section{Kaynaklar}

Arey L. 1921. An Experimental Study on Glochidia and the Factors Underlying Encystment. Journal of Experimental Zoology, 33: 463-499.

Bogan AE. 2008. Global Diversity of freshwater mussels (Mollusca, Bivalvia) in freswater. Hydrobiologia, 595: 139147.

Chamberlain T. 1934. The Glochidial Conglutinates of the Arkansas Fanshell, Cyprogenia aberti (Conrad). The Biological Bulletin, 66: 55-61.

Ercan E, Gaygusuz Ö, Tarkan AS, Reichard M, Smith C. 2013. The ecology of freshwater bivalves in the Lake Sapanca basin, Turkey. Turkish Journal of Zoology, 37: 730-738.

Kara C. 2004. Gavur Gölü (Kahramanmaraş)'nde Yaşamış Olan Unio pictorum (L., 1758)'un Bazı Biyolojik Özellikleri. KSÜ Fen ve Mühendislik Dergisi, 7(2): 9-12.

Lopes-Lima M, Kebapçı U, Van Damme D. 2014. Unio crassus. The IUCN Red List of Threatened Species2014: e. T22736A42465628. http://dx.doi.org/10.2305/IUCN.UK. 20141.RLTS.T22736A42465628.en. Downloaded on 07 April 2016.
Meglitsch P, Schram F. 1991. Invertebrate Zoology, Third Edition. New York, NY: Oxford University Press, Inc, 623s.

Mussel. 2016. Mussel Project, http://musselproject.uwsp.edu/db/db.php?view =valid $\& \mathrm{~h}=\mathrm{s} \& \mathrm{c}=\mathrm{unio}+\mathrm{cras}$ sus\&l=sci_name\&button=Submit, 11.08.2016

Nagel KO, Dümpelmann C, Pfeiffer M. 2015. Effective Growth Cessation in Adult Unio Crassus Philipsson, 1788 (Bivalvia: Unionidae) From Germany. Folia Malacologica, 23(4): 309313.

Nichols S, Newton T. 2008. The Role of Freshwater Mussels in Food Webs and Their Nutritional Requirements in Ecosystems. International Congress for Conservation Biology, Convention Center, Chattanooga, TN, 2010-11-12.

Oehlmann J, Schulte-Oehlmann U. 2003. Molluscs as Bioindicators. In: Markert BA, Breure AM, Zechmeister HG (eds.): Bioindicators and Biomonitors - Principles, Concepts and Applications. Amsterdam, Lausanne, New York, Elsevier, s. 577-635.

Ogle D. 2013. fishR Vignette - Length-Weight Relationships, Northland Collage, $11 \mathrm{p}$.

Reategui-Zirena EG, Stewart PM, Miller JM. 2013. Growth Rates and Age Estimations of the Fuzzy Pigtoe, Pleurobema strodeanum: A Species Proposed for Listing under the Endangered Species Act. Southeastern Naturalist, 12(1): 161-170.

Taeubert JE, Martinez AMP, Gum B, Geist J. 2012. The relationship between endangered thick-shelled river mussel (Unio crassus) and its host fishes. Biological Conservation, 155: 94-103.

WFD, Directive 2000/60/EC (I). Directive of the European Parliament and of the Council (establishing a framework for Community action in the field of water policy), Official Journal of the European Communities, 327/1, $72 \mathrm{p}$

Watters G. 1992. Unionids, Fishes, and the Species-Area Curve. Journal of Biogeography, 19: 491-490.

Yorulmaz B, Sukatar A, Barlas M. 2015 Comparative Analysis of Biotic Indices for Evaluation of Water Quality of Esen River in South-West Anatolia, Turkey. Fresenius Environmental Bulletin, 24(1a): 188-194.

Zar JH. 1999. Biostatistical analysis, 4th ed. Upper Saddle River, New Jersey, Prentice Hall. 929 p. 